\title{
Increased potassium intake from fruit and vegetables or supplements does not lower blood pressure or improve vascular function in UK men and women with early hypertension: a randomised controlled trial
}

\author{
Sarah E. Berry ${ }^{1}$, Umme Z. Mulla ${ }^{1}$, Philip J. Chowienczyk ${ }^{2}$ and Thomas A. B. Sanders ${ }^{1}$ * \\ ${ }^{1}$ Nutritional Sciences Division, King's College London, Franklin-Wilkins Building, 150 Stamford Street, London SE1 9NH, UK \\ ${ }^{2}$ Cardiovascular Science Division, St Thomas' Hospital, London SE1 9RT, UK
}

(Received 15 February 2010 - Revised 7 June 2010 - Accepted 8 June 2010 - First published online 2 August 2010)

K-rich fruit and vegetables may lower blood pressure (BP) and improve vascular function. A randomised controlled trial (ISRCTN50011192) with a cross-over design was conducted in free-living participants with early stages of hypertension (diastolic $\mathrm{BP}>80 \mathrm{and}<100 \mathrm{mmHg}$, not receiving BP-lowering medication) to test this hypothesis. Following a 3-week run-in period on a control diet, each subject completed four dietary 6-week dietary interventions (control + placebo capsules, an additional 20 or $40 \mathrm{mmol} \mathrm{K} / \mathrm{d}$ from fruit and vegetables or $40 \mathrm{mmol}$ potassium citrate capsules/d) using a Latin square design with a washout period $\geq 5$ weeks between the treatment periods. Out of fifty-seven subjects who were randomised, twenty-three male and twenty-five female participants completed the study; compliance to the intervention was corroborated by food intake records and increased urinary $\mathrm{K}^{+}$excretion; plasma lipids, vitamin $\mathrm{C}$, folate and homocysteine concentrations, urinary Na excretion, and body weight remained were unchanged. On the control diet, mean ambulatory $24 \mathrm{~h}$ systolic/diastolic BP were 132.3 (SD 12.0)/81.9 (SD 7.9) $\mathrm{mmHg}$, and changes (Bonferroni's adjusted $95 \% \mathrm{CI}$ ) compared with the control on the diets providing 20 and $40 \mathrm{mmol} \mathrm{K}^{+} / \mathrm{d}$ as fruit and vegetables were $0.8(-3.5,5.3) / 0.8(-1.9,3.5)$ and $1.7(-3.0,5.3) / 1.5(-1.5,4.4)$, respectively, and were $1.8(-2.1,5.8) / 1.4$ $(-1.6,4.4) \mathrm{mmHg}$ on the $40 \mathrm{mmol}$ potassium citrate supplement, and were not statistically significant. Arterial stiffness, endothelial function, and urinary and plasma isoprostane and C-reactive protein (CRP) concentrations did not differ significantly between the diets. The present study provides no evidence to support dietary advice to increase $\mathrm{K}$ intake above usual UK intakes in the subjects with early stages of hypertension.

Blood pressure: Potassium: Fruit and vegetables: Endothelial function: Arterial stiffness: Isoprostanes

Blood pressure (BP) is a major modifiable risk factor for $\mathrm{CVD}^{(1,2)}$. Hypertension is a self-amplifying condition, and diet is believed to play an important role in its genesis. Consequently, relatively small reductions $(2-5 \mathrm{mmHg})$ in BP in the population may have a large impact on cardiovascular mortality ${ }^{(3)}$. BP rises with age, and it is positively associated with BMI, alcohol and salt intake, and is negatively associated with $\mathrm{K}$ intake ${ }^{(4)}$. Cross-sectional as well as prospective cohort studies indicate that higher fruit and vegetable consumption is associated with a lower BP, and risk of stroke and $\mathrm{CHD}^{(5,6)}$. Much attention has been focused on the antioxidant nutrients (vitamin $C, \beta$-carotene and tocopherol) provided by fruit and vegetables, but randomised controlled trials on dietary supplements of these nutrients have failed to show any favourable effect on BP or on risk of $\mathrm{CVD}^{(7)}$. Phytochemicals such as flavonoids present in fruit and vegetables may influence vascular function by the way of their antioxidant properties, but evidence for their beneficial effect on CVD from prospective cohort studies is inconclusive ${ }^{(8,9)}$. The high $\mathrm{K}$ content of fruit and vegetables is a plausible mechanism to explain why high intakes of fruit and vegetables are associated with a lower risk of CVD. In support of this is a meta-analysis of oral $\mathrm{K}$ supplementation which indicated reductions in systolic $\mathrm{BP}$ of 3 and $7 \mathrm{mmHg}$ in normotensive and hypertensive subjects, respectively ${ }^{(10)}$. Furthermore, a BP-lowering effect of potassium citrate, the major form of the mineral in fruit and vegetables, has also been reported ${ }^{(11,12)}$.

The PREMIER study ${ }^{(13)}$ conducted among free-living subjects in the USA indicated that intensive dietary advice, which included advocating the consumption of ten servings of fruit and vegetables a day and increased $\mathrm{K}$ excretion by $19 \mathrm{mmol} / \mathrm{d}$, lowered systolic/diastolic BP by $5 \cdot 7 / 3.2 \mathrm{mmHg}$. The average UK intake of fruit and vegetables is three portions daily, with slightly lower intakes in low income groups ${ }^{(14,15)}$. A trial conducted in a general practice setting in the UK reported that advice to increase fruit and vegetables from three to five portions daily lowered systolic BP by $4 \mathrm{mmHg}^{(16)}$, but it was not designed to test BP as a primary outcome and this important observation requires confirmation.

The present study was designed to test the effects on BP and vascular function of increasing $\mathrm{K}$ intake from usual levels, either by increased intakes of fruit and vegetables or by supplementation, in subjects with high-normal or elevated $\mathrm{BP}$, who were not receiving BP-lowering medication.

Abbreviations: BP, blood pressure; CRP, C-reactive protein; DASH, Dietary Approaches to Stop Hypertension; FMD, flow-mediated dilatation.

* Corresponding author: Professor T. A. B. Sanders, fax +44 207848 4171, email tom.sanders@kcl.ac.uk 


\section{Subjects and methods}

\section{Subjects}

Men and women (aged 22-65 years) were recruited in three cohorts between October 2004 and November 2005, through educational institutions in London; participants included staff, family members of students and students undergoing higher education. Advertisements and flyers offering BP checks were circulated to staff, students and parents. Inclusion criteria were a seated diastolic $\mathrm{BP}>80$ and $<100 \mathrm{mmHg}$ on two occasions. The first screening visit took place in the participant's workplace/school or in a clinic. Seated BP was measured, using an automated sphygmomanometer (Omron 70CP, Tokyo, Japan), according to British Hypertension Society guidelines ${ }^{(17)}$ following a $10 \mathrm{~min}$ rest. Participants with diastolic BP $>80 \mathrm{mmHg}$ attended a clinic for further BP measurements, to provide a fasting blood sample for haematology, liver function tests and lipid profile, and to have measurements of weight and height in order to confirm eligibility to the study. Exclusion criteria included were clinical history of myocardial infarction, diabetes mellitus, renal disease, gastrointestinal disease, pancreatitis, cholestatic liver disease or cancer; current use of systemic corticosteroids, androgens, phenytoin, erythromycin, thyroid hormones, lipidlowering, BP-lowering or anticoagulant medication; cigarette smoking; history of substance abuse or alcoholism; alcohol intake exceeding a moderate intake $(>24-36 \mathrm{~g}$ alcohol/d); pregnancy or having had a baby in the last year; allergy or intolerance to intervention foods; unwillingness to refrain from the use of dietary supplements; weight loss $>3 \mathrm{~kg}$ in the preceding 2 months; BMI $<20$ and $>35 \mathrm{~kg} / \mathrm{m}^{2}$; and $\mathrm{BP}$ and other risk factors that make them eligible for drug treatment of raised $\mathrm{BP}$ according to the British Hypertension Society guidelines ${ }^{(17)}$. Cross-sectional surveys indicate that in the UK about 30 and $50 \%$ are hypertensive (seated systolic $\mathrm{BP}>140 / 90 \mathrm{mmHg}$ measured using the Omron device) among those aged 45-54 and 54-64 years, respectively ${ }^{(18)}$. However, these estimates are based on single occasion measures of $\mathrm{BP}$, and it is well known that $\mathrm{BP}$ regresses towards the mean on repeated measures as demonstrated in the present study where the fall in seated systolic BP/diastolic $\mathrm{BP}$ between first and second screening visits was $7 / 3 \mathrm{mmHg}$. We chose to include diastolic $\mathrm{BP}>80$ and $<100 \mathrm{mgHg}$ as an indicator of early hypertension as it reflects increased systemic vascular resistance and because values above $75 \mathrm{mmHg}$ are associated with increased risk of CHD and stroke ${ }^{(2)}$. The present study was conducted according to the guidelines laid down in the Declaration of Helsinki, and all procedures involving human subjects/patients were approved by the Research Ethics Committee of King's College London (reference 03/04-105). Written informed consent was obtained from all the subjects.

\section{Experimental design and procedures}

A randomised placebo-controlled cross-over Latin square design was used to compare three experimental treatments $v$. a control treatment. Participants were randomly allocated to the various treatment sequences by a computer so that a similar numbers of subjects were on each treatment at any one time. Participants underwent a 3-week run-in period on the control level of fruit and vegetable intake (providing $15 \mathrm{mmol} \mathrm{K} / \mathrm{d}$ ) before undertaking the allocated treatment sequence. This run-in period was to habituate the subjects to the dietary intervention, the ambulatory BP measurements and the vascular function measurements. Each treatment period lasted 6 weeks and was separated by a minimum of 5 weeks, where the subjects were allowed to revert to their usual diet (Fig. 1). The experimental treatments compared additional 20 or $40 \mathrm{mmol} \mathrm{K} / \mathrm{d}$ provided as fruit and vegetables, or $40 \mathrm{mmol} / \mathrm{d}$ provided as potassium citrate capsules (two capsules taken four times a day). The control treatment involved the consumption of placebo capsules (two capsules taken four times a day) and an intake of fruit and vegetables similar to the average UK intake. Participants were blinded to the allocation of placebo and potassium citrate capsules, which were matched in size and colour. The potassium citrate capsules were a slow-release formulation manufactured for the project by Penn Pharmaceuticals Limited (Tredegar, Gwent, UK). Researchers undertaking vascular function measurements were blinded to the treatment allocation.

For the run-in period, control treatment period and potassium citrate supplementation treatment period, the participants were instructed to consume an amount of fruit and vegetables providing $15 \mathrm{mmol} \mathrm{K} / \mathrm{d}$ which is equivalent to the contribution made by these foods in the average UK diet ${ }^{(15,19)}$. To consume the additional 20 or $40 \mathrm{mmol} \mathrm{K} / \mathrm{d}$ as fruit and vegetables, the participants were asked to consume a total of 7 and 11 units of $\mathrm{K}$ daily, respectively. Participants consumed their habitual intakes of fruit and vegetables during the washout periods.

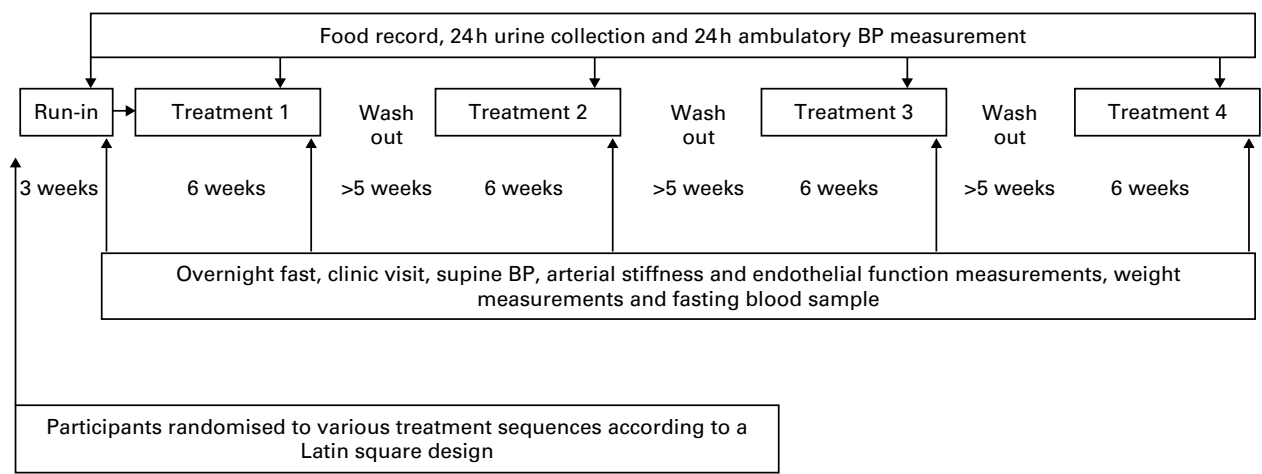

Fig. 1. Outline of the study design. BP, blood pressure. 
Personalised dietary advice was provided as a unit system ( 1 unit $=5 \mathrm{mmol} \mathrm{K}$ ), and the participants were provided with fruit and vegetables free of cost for the duration of the intervention. Sample menus and instructions on how to prepare the fruit and vegetables were provided so that they retained maximum nutritional value (i.e. cooking in minimum volume of water and avoiding exposure of cut vegetable to air, light or heat for long periods). Written advice, cards illustrating the portion sizes and recommended intakes of fruit and vegetables at each level of intake were provided. They were discouraged from consuming fruit in the form of syrup or pickled vegetables and those preserved in oil. Furthermore, in line with the then current UK Department of Health advice, they were advised that fruit juice $(150 \mathrm{ml})$ only counted for one portion. Participants were advised to avoid using soya products throughout the study because of their high $\mathrm{K}$ content. Potatoes were not included as a portion of fruit and vegetables.

\section{Compliance to the dietary intervention}

During the dietary treatments, the participants were contacted via telephone on a weekly basis to arrange fruit and vegetable delivery orders and to confirm that they were following the dietary instructions. Participants were requested to complete food record cards detailing the fruit and vegetables consumed during each treatment as well as to make $24 \mathrm{~h}$ urine collections (week 3 of run-in period and weeks 5-6 of each treatment period) to ascertain compliance to the treatment by measurement of urinary $\mathrm{K}$ excretion. A controlled feeding study ${ }^{(20)}$ had established the reliability of the measurement of $24 \mathrm{~h}$ urinary $\mathrm{K}$ to indicate $\mathrm{K}$ intake; this showed that urinary $\mathrm{K}$ excretion increased by $30 \mathrm{mmol} / \mathrm{d}$ following a $40 \mathrm{mmol}$ potassium citrate supplement, and by 14 and $29 \mathrm{mmol} / \mathrm{d}$ following the provision of an additional 20 and $40 \mathrm{mmol} / \mathrm{d} \mathrm{K}$ as fruit and vegetables, indicating that approximately $75 \%$ of the additional $\mathrm{K}$ is recovered in urine.

\section{Study outcomes}

The primary outcome was a change in ambulatory BP measured over $24 \mathrm{~h}$ using an A\&D TM-2430 device (ScanMed, Moreton-in-Marsh, Gloucester, UK) which is graded A/A according to the current guidelines ${ }^{(21)}$. The device was set to record $\mathrm{BP}$ measures at $30 \mathrm{~min}$ intervals during the day and hourly during the night, and the participants maintained a record of the activities of the recording period. Measurements were made in the last week of each study period but were not made on the day before the collection of blood sample. On the last day of each study period, the participants fasted overnight before attending a clinic visit at St Thomas' Hospital, London, UK. Vascular function measurements were performed with the participant supine in a quiet, darkened and temperaturecontrolled room $\left(23^{\circ} \mathrm{C}\right)$. Supine BP was measured in triplicate after $15 \mathrm{~min}$ rest followed by triplicate measurements of carotid to femoral pulse wave velocity and radial pulse wave analysis by applanation tonometry using the SphygomoCor systems (version 7.01; AtCor Medical, Sydney, NSW, Australia). Flow-mediated dilatation (FMD) of the brachial artery was performed on the right arm, according to the international recommendations ${ }^{(22)}$. Endothelial independent dilation was determined in response to $25 \mu \mathrm{g}$ glycerol trinitrate that was administered sublingually. Following these measurements, fasting blood samples were collected for the measurement of serum total cholesterol, HDLcholesterol, TAG, glucose and insulin ${ }^{(23)}$, high-sensitivity C-reactive protein (CRP) (P.Z. Cormay, Lublin, Poland), soluble intracellular adhesion molecule (R\&D Systems Europe, Abingdon, Oxon, UK), vitamin $\mathrm{C}^{(24)}$, carotenoids and tocopherols ${ }^{(25)}, 8$-isoprostane $\mathrm{F}_{2 \alpha}{ }^{(26)}$, folate and homocysteine ${ }^{(27)}$.

Urine was collected in containers without additives, and the urinary $\mathrm{Na}$ and $\mathrm{K}$ were determined using ion-selective electrodes, and creatinine was determined by the Jaffé reaction on ADVIA 1650 analysers (Bayer Diagnostics, Newbury, UK). Urinary 2,3-dinor-8-isoprostane $F_{2 \alpha}$ was determined using a time-resolved immunofluorescence assay ${ }^{(28)}$.

\section{Statistical analysis}

Sample size calculations were based on thirty-two subjects completing the study to detect a $4 \mathrm{mmHg}$ change in systolic BP (based on $80 \%$ power, $P=0.01$ ) by ambulatory $\mathrm{BP}$ monitoring assuming a within-subject SD for systolic BP of $5 \mathrm{mmHg}$; this sample size gave power to detect changes in the main secondary outcomes of $1 \%$ for FMD and $0.8 \mathrm{~m} / \mathrm{s}$ for carotid to femoral pulse wave velocity. The project set out to recruit forty-eight participants in order to allow for a $30 \%$ drop-out rate. Statistical analysis was conducted using SPSS/PC version 14.0 for Windows. The endpoint analysis was on an intention-to-treat basis and involved all forty-eight participants who completed the study. Data were analysed by repeated measures ANOVA of the four treatments with the value for the run-in period as a covariate. Where the overall $F$ value from the ANOVA indicated a statistically significant between-treatment effect, post hoc comparisons were made between the various treatment levels, and the change from the control value is shown with $95 \%$ CI corrected for multiple comparisons using Bonferroni's multiple comparison test. CRP was analysed using non-parametric tests. Correlations between variables were made on the average of five within-subject measures using Spearman's correlation.

\section{Results}

Fig. 2 shows the CONSORT diagram of the flow of subjects through the trial. Mean systolic/diastolic BP fell by $7 \cdot 6$ (SD 10.3)/3.1 (SD 6.0) $\mathrm{mmHg}$ between the first and second screening visits. Out of the fifty-seven participants who were randomised to treatment sequences, five withdrew during the run-in period, one withdrew during the first intervention for personal reasons, two were withdrawn from the study and placed on BP-lowering medication, and one withdrew from the study during the last intervention due to a brain tumour; data for the analysis were available for forty-eight subjects. The participants were in the upper tertile of the BP distribution of those screened. The mean seated BP (systolic/diastolic) of the fifty-seven participants at randomisation was $137 / 89 \mathrm{mmHg}$ and of the fortyeight participants (twenty-five female, twenty-three male) who completed the study was $137 / 89 \mathrm{mmHg}$; twenty-nine participants were of European, nine were of Asian and ten were of African ethnic origin, and their details are 


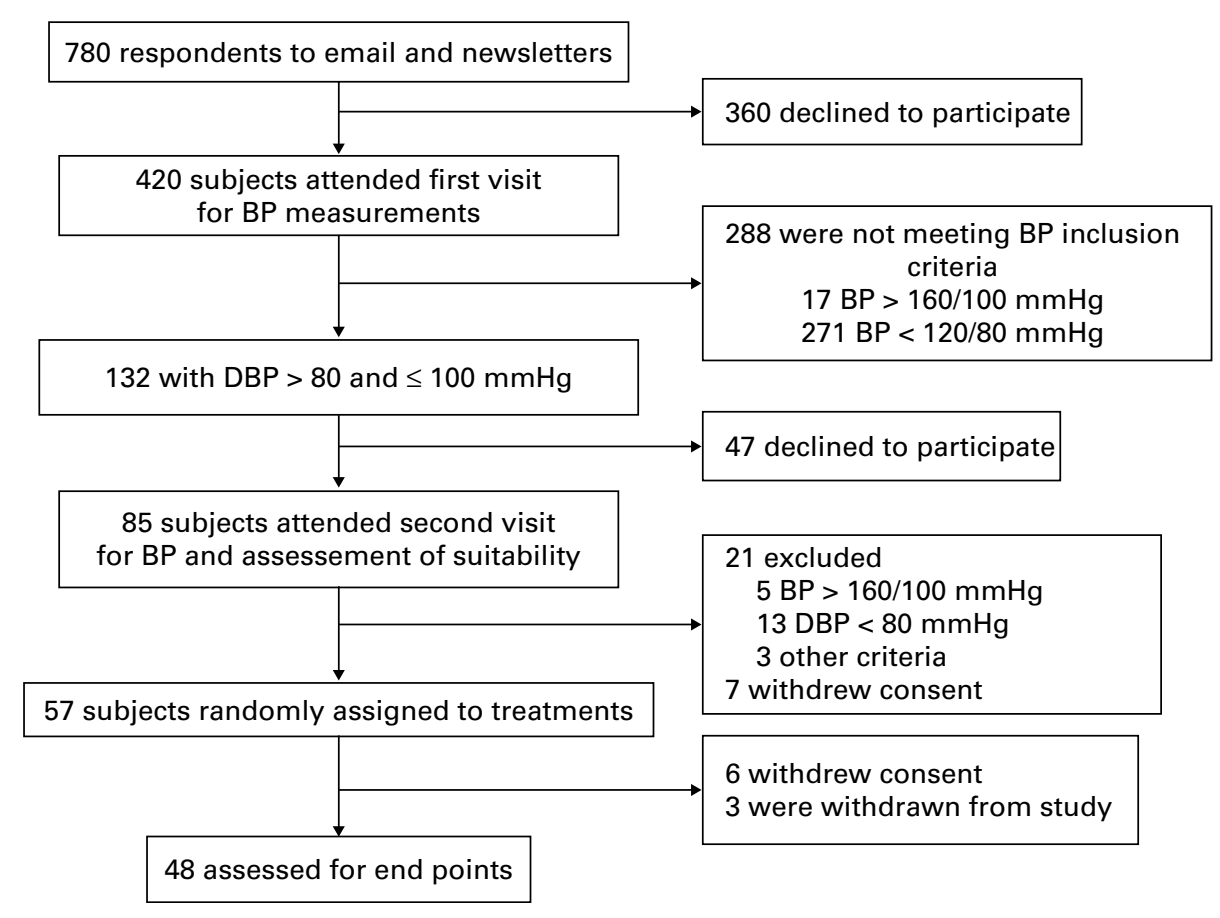

Fig. 2. CONSORT diagram of the flow of subjects through the study. BP, blood pressure; DBP, diastolic BP.

shown in Table 1. Using the British Hypertension Society classification based on seated $\mathrm{BP}^{(17)}$, twenty-three participants had grade 1 hypertension, eighteen had high-normal $\mathrm{BP}$, and seven had normal BP. Most of the participants $(88 \%)$ were overweight or obese $\left(\mathrm{BMI}>25 \mathrm{~kg} / \mathrm{m}^{2}\right)$; however, fasting plasma glucose concentrations were elevated $(>5.5 \mathrm{mmol} / \mathrm{l})$ in only two participants. Serum cholesterol and HDL-cholesterol concentrations were typical for the UK adult population; $71 \%$ of the participants had a LDLcholesterol concentration $>3.0 \mathrm{mmol} / \mathrm{l}$, and $8 \%$ had low

Table 1. Details of participants completing the study (Mean values and standard deviations)

\begin{tabular}{|c|c|c|c|c|}
\hline & \multicolumn{2}{|c|}{ Women } & \multicolumn{2}{|c|}{ Men } \\
\hline & Mean & SD & Mean & SD \\
\hline \multicolumn{5}{|l|}{ Ethnicity $n(\%)$} \\
\hline White European & 13 & 52 & 16 & 70 \\
\hline Black African & 9 & 36 & 1 & 4 \\
\hline Asian & 3 & 1 & 6 & 26 \\
\hline Age (years) & $44 \cdot 8$ & $8 \cdot 2$ & $45 \cdot 5$ & $10 \cdot 6$ \\
\hline Seated systolic BP (mmHg) & $136 \cdot 0$ & $9 \cdot 1$ & $139 \cdot 4$ & $9 \cdot 7$ \\
\hline Seated diastolic BP (mmHg) & $89 \cdot 2$ & $5 \cdot 7$ & 88.0 & $6 \cdot 6$ \\
\hline BMI $\left(\mathrm{kg} / \mathrm{m}^{2}\right)$ & 29.2 & 4.3 & $27 \cdot 7$ & $3 \cdot 2$ \\
\hline Waist circumference (cm) & $90 \cdot 2$ & $10 \cdot 0$ & 98.4 & $9 \cdot 8$ \\
\hline Body fat (\%) & $37 \cdot 7$ & $5 \cdot 9$ & $23 \cdot 9$ & $5 \cdot 5$ \\
\hline Serum cholesterol (mmol/l) & $5 \cdot 36$ & 1.05 & $5 \cdot 61$ & 0.83 \\
\hline Serum LDL-cholesterol (mmol/l) & 3.24 & 0.86 & 3.63 & $0 \cdot 71$ \\
\hline Serum HDL-cholesterol (mmol/li) & 1.65 & 0.36 & 1.38 & 0.37 \\
\hline Serum TAG $(\mathrm{mmol} / \mathrm{l})$ & 1.06 & 0.69 & 1.31 & 0.59 \\
\hline Plasma glucose $(\mathrm{mmol} / \mathrm{l})$ & 4.97 & 0.30 & $5 \cdot 38$ & 0.43 \\
\hline Plasma homocysteine $(\mu \mathrm{mol} / \mathrm{l})$ & & 3.8 & $12 \cdot 1$ & 3.4 \\
\hline Plasma CRP $\left(\mathrm{mg} / \mathrm{l}^{\star}\right.$ & \multicolumn{2}{|c|}{$1 \cdot 1(0.1-2 \cdot 6)$} & \multicolumn{2}{|c|}{$1 \cdot 0(0.2-1 \cdot 8)$} \\
\hline
\end{tabular}

$\mathrm{BP}$, blood pressure; CRP, C-reactive protein.

${ }^{*}$ Median with interquartile range.
HDL-cholesterol concentrations $(<0.9 \mathrm{mmol} / \mathrm{l}$ for males and $<1.1 \mathrm{mmol} / 1$ for females). Most of the participants $(83 \%)$ had waist measurements that were greater than $94 \mathrm{~cm}$ for males and $80 \mathrm{~cm}$ for females, and $29 \%$ of the participants met the International Diabetes Federation definition of the metabolic syndrome ${ }^{(29)}$.

\section{Compliance to the intervention}

Capsule counts indicated that $98.4 \%$ (SD 11.4) of potassium citrate and $94.9 \%$ (SD 14.5) of placebo capsules were taken. Mean intakes of $\mathrm{K}$ from fruit and vegetables calculated from the food record cards were close to those planned (Fig. 3). The mean intakes of fruit were 162 (SD 53), 165 (SD 79), 336 (SD 118), 402 (SD 190) g/d on control, $40 \mathrm{mmol}$ potassium citrate supplement, 20 and $40 \mathrm{mmol} \mathrm{K}$ from fruit and vegetables, respectively; corresponding intakes of vegetables were 129 (SD 39), 128 (SD 45), 197 (SD 85) and 238 (SD 93) g/d, respectively. The fruit intake was mainly derived from bananas, apples, citrus fruits, pears, plums, peaches/ nectarines, dried fruit and berries (mainly strawberries), and the vegetable intake was mainly derived from tomatoes, carrots, capsicum peppers, green vegetables (spinach, lettuce, cabbage and green beans) and mixed vegetables. Table 2 shows that urinary $\mathrm{K}$ excretion increased in line with the values obtained in the pilot study, and the increment on $40 \mathrm{mmol}$ additional $\mathrm{K}$ from fruit and vegetables did not differ from that obtained following the $40 \mathrm{mmol}$ potassium citrate supplement. The ratio of $\mathrm{Na}: \mathrm{K}$ was significantly lower on the experimental treatments compared with the control treatment. Plasma carotenoids, tocopherols and $\mathrm{Na}$ excretion did not differ significantly between the treatments. No relationship was found between plasma vitamin $\mathrm{C}$ concentration and increasing fruit and vegetable intake, but this was 


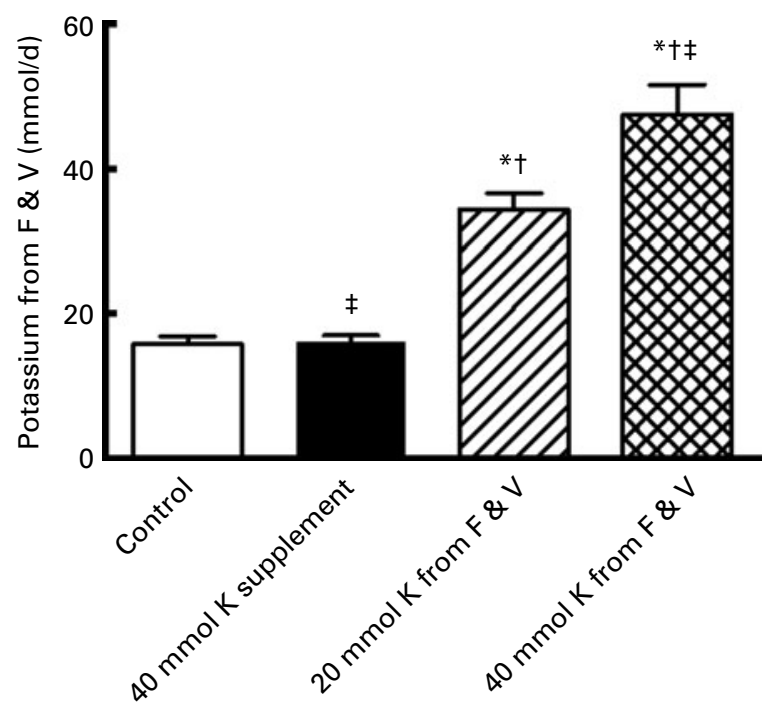

Fig. 3. Self reported potassium (K) intake from fruit and vegetables (F\&V) according to the dietary treatment (geometric mean with $95 \% \mathrm{Cl}, P<0.001$ for both). Probability was estimated from repeated measures of ANOVA of the four treatments with run-in value as covariate. ${ }^{*}$ Mean values were significantly different from control value $(P<0 \cdot 01)$. $†$ Mean values were significantly different from $40 \mathrm{mmol} \mathrm{K}$ value $(P<0.01)$. $¥$ Mean values were significantly different from $20 \mathrm{mmol} \mathrm{K}$ value $(P<0.01)$.

not unexpected as the participants were non-smokers and habitual intakes of vitamin $\mathrm{C}$ are relatively high in the UK population even in low income groups ${ }^{(14)}$. Nor were changes in serum folate observed, but this is not surprising as the major source of fruit and vegetables consumed in the present study was not rich in folate.

Body weight remained stable throughout the study, and there were no reported side-effects in any of the treatment groups.

\section{Primary and secondary outcomes}

On an average thirty awake and eight asleep ambulatory BP readings were made in each $24 \mathrm{~h}$ period. Awake and asleep ambulatory systolic/diastolic BP following the 3-week run-in period were 138.5 (SD 14.4)/87 (SD 7.3) and 116 (SD 13.9)/71 (SD 7.3) $\mathrm{mmHg}$, respectively, and were not statistically significantly different from 136.3 (SD 12.8)/85 (SD 8.9) and $116 \cdot 3$ (SD 15.3)/70 (SD 8.5) $\mathrm{mmHg}$ on the control treatment. Table 3 shows the changes in ambulatory BP, arterial stiffness and endothelial function compared with the control treatment which were not statistically significant. There was no evidence to indicate that higher intakes of $K$ provided by either supplementation or intakes of fruit and vegetables resulted in lower $\mathrm{BP}$, and that the changes were well below the $4 \mathrm{~mm}$ difference in systolic BP so that the study was powered to detect. These conclusions were not altered when the subjects with stage 1 hypertension were analysed separately. The mean changes and $95 \%$ CI for FMD and carotid to femoral pulse wave velocity were well inside the size of effect that the study was powered to detect and they did not differ between the treatments.

\section{Cardiovascular risk factors}

There were no statistical significant treatment-related changes in serum total cholesterol, HDL-cholesterol, TAG, plasma homocysteine, insulin, glucose, CRP, plasma 8-isoprostane $\mathrm{F}_{2 \alpha}$ concentrations and urinary 8-isoprostane $\mathrm{F}_{2 \alpha}$ metabolite excretion (Table 4). In the female participants, mean serum intracellular adhesion molecule-1 was $2.14 \mathrm{mg} / 1$ (95\% CI $2 \cdot 00,2 \cdot 30$ ) on the treatment providing $40 \mathrm{mmol} \mathrm{K}$ as fruit and vegetables and was significantly greater $(P<0.05)$ than $2.53 \mathrm{mg} / 1(95 \%$ CI $2.33,2.75)$ on the control treatment, but no treatment-related differences in this analyte were noted between the male participants. Plasma 8-isoprostane $\mathrm{F}_{2 \alpha}$ concentrations were correlated with total and LDL-cholesterol concentrations $(\rho=0.563$ and 0.535 ; both $P<0.0001)$.

\section{Discussion}

The present study sets out to test the hypothesis that an increased intake of $\mathrm{K}$ (above the average UK intake) provided by raising fruit and vegetable intake lowers BP and improves

Table 2. Body weight, and plasma vitamin $\mathrm{C}$, carotenoids, tocopherol concentrations, urinary potassium and sodium excretion in participants (female $n 25$, male $n 23$ ) according to additional intake of potassium (K) provided by increased fruit and vegetable intake or a potassium citrate supplement (Mean values and $95 \%$ confidence intervals)

\begin{tabular}{|c|c|c|c|c|c|c|c|c|c|}
\hline & & & \multicolumn{4}{|c|}{ Increased fruit and vegetables } & \multirow{2}{*}{\multicolumn{2}{|c|}{$\begin{array}{c}\text { Potassium citrate } \\
40 \mathrm{mmol} \mathrm{K/d}\end{array}$}} & \multirow[b]{3}{*}{$P^{*}$} \\
\hline & \multicolumn{2}{|c|}{ Control } & \multicolumn{2}{|c|}{$20 \mathrm{mmol} \mathrm{K/d}$} & \multicolumn{2}{|c|}{$40 \mathrm{mmol} \mathrm{K/d}$} & & & \\
\hline & Mean & $95 \% \mathrm{Cl}$ & Mean & $95 \% \mathrm{Cl}$ & Mean & $95 \% \mathrm{Cl}$ & Mean & $95 \% \mathrm{Cl}$ & \\
\hline Body weight $(\mathrm{kg})$ & $80 \cdot 3$ & $79 \cdot 6,81 \cdot 0$ & $80 \cdot 2$ & $79 \cdot 3,81 \cdot 1$ & $80 \cdot 6$ & $79 \cdot 9,81 \cdot 3$ & $80 \cdot 2$ & $79 \cdot 4,81 \cdot 0$ & 0.340 \\
\hline Plasma vitamin $\mathrm{C}(\mu \mathrm{mol} / \mathrm{l}) \dagger$ & $78 \cdot 3$ & $71 \cdot 6,85 \cdot 6$ & $78 \cdot 2$ & $72 \cdot 2,84 \cdot 7$ & $83 \cdot 3$ & $75 \cdot 7,91 \cdot 6$ & $75 \cdot 1$ & $67 \cdot 9,83 \cdot 1$ & 0.716 \\
\hline Serum folate $(\mu \mathrm{mol} / \mathrm{l})$ & $9 \cdot 6$ & $8 \cdot 7,10 \cdot 6$ & $9 \cdot 1$ & $8 \cdot 3,9 \cdot 8$ & $9 \cdot 3$ & $8 \cdot 4,10 \cdot 1$ & 9.5 & $8 \cdot 6,10 \cdot 4$ & 0.886 \\
\hline Plasma tocopherol ( $\mu \mathrm{mol} / \mathrm{mmol}$ cholesterol) & 6.9 & $6 \cdot 0,7 \cdot 8$ & 6.9 & $6 \cdot 4,7.5$ & $6 \cdot 7$ & $6 \cdot 2,7 \cdot 2$ & $6 \cdot 7$ & $6 \cdot 1,7 \cdot 3$ & 0.862 \\
\hline Plasma $\alpha$-carotene $(\mu \mathrm{mol} / \mathrm{mmol}$ cholesterol $)$ & 0.02 & $0.02,0.03$ & 0.02 & $0.02,0.03$ & 0.02 & $0.02,0.03$ & 0.02 & $0.02,0.03$ & 0.939 \\
\hline Plasma $\beta$-carotene $(\mu \mathrm{mol} / \mathrm{mmol}$ cholesterol) & 0.07 & $0.06,0.08$ & 0.07 & $0.06,0.08$ & 0.07 & $0.06,0.08$ & 0.07 & $0.06,0.08$ & 0.740 \\
\hline Urinary $\mathrm{Na}(\mathrm{mmol} / \mathrm{d}) \dagger$ & 106 & 93,121 & 116 & 101,134 & 124 & 107,144 & 113 & 99,129 & 0.683 \\
\hline Urinary $\mathrm{K}(\mathrm{mmol} / \mathrm{d})$ & 60 & 52,67 & $75 \ddagger$ & 67,83 & $84 \ddagger$ & 74,94 & 87‡ & 77,96 & 0.0001 \\
\hline Urinary Na:K & $2 \cdot 3$ & $1 \cdot 8,2 \cdot 8$ & 1.9 & $1 \cdot 5,2 \cdot 3$ & $1.8 \ddagger$ & $1 \cdot 5,2 \cdot 1$ & $1.5 \ddagger$ & $1 \cdot 4,1 \cdot 7$ & 0.008 \\
\hline
\end{tabular}

* Probability estimated from repeated measures ANOVA of the four treatments with the run-in value as covariate.

$\dagger$ Geometric mean.

$\ddagger P<0.05$ compared with control; Bonferroni's multiple comparison test. 
Table 3. Ambulatory and supine clinic systolic and diastolic blood pressure (SBP, DBP in $\mathrm{mmHg}$ ), carotid to femoral pulse wave velocity (PWV $\mathrm{c}_{-\mathrm{f}}$ ), peripheral augmentation index (PAI), flow-mediated dilatation (FMD) and glycerol trinitrate (GTN) responses of the brachial artery in participants (male $n$ 23, female $n 25$ ) during the control intervention, and changes from control following increased intakes of potassium (K) provided by increased fruit and vegetable intake or a potassium citrate supplement

(Mean values and standard deviations; mean values and $95 \%$ confidence intervals)

\begin{tabular}{|c|c|c|c|c|c|c|c|c|c|}
\hline & & & \multicolumn{4}{|c|}{ Increased fruit and vegetables } & \multirow{2}{*}{\multicolumn{2}{|c|}{$\begin{array}{c}\text { Potassium citrate } \\
40 \mathrm{mmol} \mathrm{K/d}\end{array}$}} & \multirow[b]{3}{*}{$P \dagger$} \\
\hline & \multicolumn{2}{|c|}{ Control } & \multicolumn{2}{|c|}{$20 \mathrm{mmol} \mathrm{K/d}$} & \multicolumn{2}{|c|}{$40 \mathrm{mmol} / \mathrm{d}$} & & & \\
\hline & Mean & SD & Mean change & $95 \% \mathrm{Cl}^{*}$ & Mean change & $95 \% \mathrm{Cl}$ & Mean change & $95 \% \mathrm{Cl}$ & \\
\hline \multicolumn{10}{|c|}{ Ambulatory measurements } \\
\hline $24 \mathrm{~h}$ SBP & $132 \cdot 3$ & $12 \cdot 0$ & 0.8 & $-3 \cdot 5,5 \cdot 0$ & 1.7 & $-3 \cdot 0,5 \cdot 3$ & 1.8 & $-2 \cdot 1,5 \cdot 8$ & 0.129 \\
\hline Awake SBP & $136 \cdot 0$ & $12 \cdot 9$ & $1 \cdot 7$ & $-2 \cdot 7,6 \cdot 8$ & 4.0 & $-0.1,8.0$ & $2 \cdot 1$ & $-2 \cdot 2,6 \cdot 3$ & 0.623 \\
\hline Asleep SBP & $117 \cdot 6$ & $14 \cdot 8$ & $-1 \cdot 0$ & $-7 \cdot 2,5 \cdot 2$ & $-1 \cdot 8$ & $-7 \cdot 1,3.5$ & 0.5 & $-6 \cdot 1,7 \cdot 1$ & 0.092 \\
\hline $24 \mathrm{~h}$ DBP & 81.9 & 7.9 & 0.8 & $-1.9,3.5$ & 1.5 & $-1.5,4.4$ & 1.4 & $-1 \cdot 6,4 \cdot 4$ & 0.766 \\
\hline Awake DBP & $85 \cdot 1$ & 8.5 & 1.0 & $-2 \cdot 2,4 \cdot 1$ & $2 \cdot 4$ & $-0.7,5.5$ & 0.8 & $-3 \cdot 0,4.5$ & 0.626 \\
\hline Asleep DBP & $70 \cdot 3$ & $7 \cdot 6$ & 1.5 & $-2 \cdot 1,5 \cdot 1$ & 0.8 & $-2 \cdot 9,4.5$ & $2 \cdot 0$ & $-1 \cdot 7,5 \cdot 7$ & 0.390 \\
\hline \multicolumn{10}{|c|}{ Clinic supine measurements } \\
\hline SBP & $122 \cdot 2$ & $13 \cdot 0$ & 1.9 & $-1.5,5.4$ & 0.7 & $-2 \cdot 8,4 \cdot 2$ & -1.5 & $-4 \cdot 3,1 \cdot 3$ & 0.452 \\
\hline DBP & 76.9 & 7.5 & 1.0 & $-1 \cdot 2,3 \cdot 2$ & 0.3 & $-1.8,2.5$ & -0.3 & $-2 \cdot 1,1 \cdot 6$ & 0.908 \\
\hline$P W V_{c-f}(m / s)$ & $7 \cdot 8$ & $1 \cdot 2$ & 0.1 & $-0.3,0.4$ & 0.0 & $-0.3,0.3$ & 0.1 & $-0.3,0.4$ & 0.140 \\
\hline $\mathrm{PAI}(\%)$ & $75 \cdot 6$ & $5 \cdot 5$ & 0.8 & $-2 \cdot 0,3 \cdot 6$ & -0.1 & $-2 \cdot 9,2 \cdot 7$ & 0 & $-2 \cdot 8,2 \cdot 8$ & 0.605 \\
\hline FMD (\%) & $6 \cdot 7$ & 1.9 & 0.1 & $-0.6,0.8$ & 0.3 & $-0.5,1.0$ & -0.1 & $-0.9,0.7$ & 0.074 \\
\hline GTN (\%) & $11 \cdot 7$ & 3.1 & -0.3 & $-1 \cdot 8,1 \cdot 1$ & -0.4 & $-1 \cdot 6,0.8$ & -0.5 & $-1 \cdot 7,0 \cdot 8$ & 0.732 \\
\hline
\end{tabular}

* Adjusted for multiple comparisons using the Bonferroni method.

$\dagger$ Estimated from repeated measures ANOVA of the four treatments with run-in value as covariate.

vascular function in early hypertension. A $4 \mathrm{~mm}$ difference in systolic BP was selected as being of clinical significance and also because a previous report ${ }^{(16)}$ indicated that this would be achieved by a single session of dietary advice to consume two additional portions of fruit and vegetables daily. In that study, which used a parallel design, the control group received no intervention which may have biased the trial. Our inability to demonstrate a BP-lowering effect is unlikely to be a consequence of poor compliance or measurement error.

Most K supplementation studies have used a parallel design, and as the common standard deviation is about $12 \mathrm{mmHg}$ for systolic BP, a sample size of about 140 subjects per group is required to detect a $4 \mathrm{~mm}$ change in $\mathrm{BP}$ at $P=0.05$ and $80 \%$ power. The use of a cross-over design provides greater statistical power to detect changes in BP than a parallel design because there is a strong correlation between repeat measurements within the same subject. However, the weakness of cross-over studies is that they can be confounded by carry-over effects and seasonal variations. This can be avoided by the use of a washout period between the treatments and the allocation of treatment sequences using a Latin square design to balance out seasonal variations between the treatments as observed in the present study. The use of a matched placebo capsule in the reference treatment is also important as any intervention may have an effect. Post hoc power analysis of the results of present study showed that it had $80 \%$ power to detect a $3 \mathrm{mmHg}$ change in systolic $\mathrm{BP}$ at $P=0.05$ indicating that it is unlikely that a change of this magnitude was missed due to insufficient sample size. Increased $\mathrm{K}$ intake through increased fruit and vegetable consumption might lower systolic BP by $2 \mathrm{mmHg}$, which would be of significance to the population attributable risk of CVD. However, a parallel designed study with 564 participants in each arm or a cross-over study with 106 participants would be required to prove this.
The present study provides no evidence for the beneficial effects on endothelial function, measured in the fasting state by changes in FMD or on indices ${ }^{(30)}$ of lipid peroxidation (plasma or urinary 2,3-dinor-8-isoprostane $F_{2 \alpha}$ ). However, a novel observation was the relatively strong correlation between plasma 8-isoprostane concentration and total and LDL-cholesterol concentrations. The lower soluble intracellular adhesion molecule-1 in women on the highest level of fruit and vegetable intake requires confirmation as this difference could have arisen by chance. It is possible that transient changes in endothelial function in the postprandial period may occur following the consumption of flavonoid-rich fruit and vegetables. In contrast to our findings, He et al. ${ }^{(31)}$ reported improvements in FMD with values of $5.8 \%$ (SD 4.4) on $64 \mathrm{mmol}$ potassium chloride/d, $4.6 \%$ (SD 2.9) on $64 \mathrm{mmol}$ potassium bicarbonate/d compared with $3.1 \%$ (SD 2.5) on placebo in forty-two mildly hypertensive participants in a cross-over study. However, measurement of FMD is subject to substantial operator error and the influence of cigarette smoking and passive smoking. In the present study, the participants were non-smokers, and values for FMD were higher. An improvement in endothelial function as measured by the changes in forearm blood flow was reported in a parallel designed randomised controlled trial in 117 hypertensive participants ${ }^{(32)}$, which included cigarette smokers, when they changed from a diet providing a very low intake of fruit and vegetables (one portion a day) to diets providing higher intakes (three or five portions). We were also unable to confirm an effect of $\mathrm{K}$ on arterial stiffness ${ }^{(31)}$. However, it is to be noted that there were changes in arterial stiffness that the study ranged from 0.5 to $0.8 \mathrm{~m} / \mathrm{s}$ and as we estimated that anything less than $0.8 \mathrm{~m} / \mathrm{s}$ could be a type 2 error. He et al. also reported improved left ventricular filling function with $\mathrm{K}$ supplementation. It is possible that higher intakes of $\mathrm{K}$ than that were used in the present study have a favourable effect of 
arterial stiffness and other indices of cardiovascular function. However, to provide an additional $64 \mathrm{mmol} \mathrm{K}$ would require consuming about $1 \mathrm{~kg}$ of fruit and vegetables daily.

Our failure to detect a statistically significant reduction in BP-lowering effect with increased $\mathrm{K}$ intake is in agreement with another UK cross-over trial by $\mathrm{He}$ et al. $^{(31)}$ who used even higher intakes of $\mathrm{K}$. These findings are in agreement with a Cochrane systematic review that concluded that there was no statistically significant effect of $\mathrm{K}$ on $\mathrm{BP}$ in patients with hypertension ${ }^{(33)}$. However, this review did note significant heterogeneity between trials. K might only lower BP when changing from very low intakes to higher intakes. In support of this is the observation that the fall in BP in the Dietary Approaches to Stop Hypertension (DASH)-2 study $^{(34)}$ with increased $\mathrm{K}$ excretion occurred from a much lower value $(41 \mathrm{mmol} / \mathrm{d})$ than in our study or that of $\mathrm{He}$ et al. ${ }^{(31)}$. Variability in the response to $\mathrm{K}$ might also depend upon the activity of the renin-angiontensin system, which declines with age and shows some marked variations between individuals. Low renin activity is more prevalent among people of African ethnic origin ${ }^{(35)}$, and large changes have been reported in some African K supplementation studies ${ }^{(33)}$. The activity of the renin-angiotensin system was not evaluated in the present study but should be considered in future studies.

Salt intake may also influence the BP-lowering effect of K as indicated in the meta-analysis by Whelton et al. ${ }^{(10)}$ where the BP-lowering effect was only statistically significant when urinary Na excretion was $>165 \mathrm{mmol} / \mathrm{d}$. Salt intakes have fallen in the UK, and the level of urinary Na excretion was well below $165 \mathrm{mmol} / \mathrm{d}$ threshold in our study and that of $\mathrm{He}$ et al. ${ }^{(31)}$. Braschi \& Naismith ${ }^{(12)}$ reported falls in seated BP of systolic/diastolic BP of $6.7 / 4.3 \mathrm{mmHg}$ with a $30 \mathrm{mmol}$ potassium citrate and of $5 \cdot 2 / 4.3 \mathrm{mmHg}$ with $30 \mathrm{mmol}$ potassium chloride in predominantly normotensive subjects. However, baseline urinary $\mathrm{K}$ and $\mathrm{Na}$ excretion were broadly similar to the present study. A major limitation of that study was the use of $\mathrm{Hg}$ sphygmomanometers, which is subject to observer bias. The failure of the present study to confirm this finding is puzzling especially as we used the same potassium citrate supplement and placebo capsules. In both our study and that of $\mathrm{He}$ et al. ${ }^{(31)}$, the participants were overweight/obese (mean BMI $29 \mathrm{~kg} / \mathrm{m}^{2}$ ), whereas in the study of Braschi \& Naismith, the mean BMI was below $25 \mathrm{~kg} / \mathrm{m}^{2}$ and the subjects were younger (mean age 35 years). It is possible that overweight/obesity abrogates the BP-lowering effect of $\mathrm{K}$.

The DASH study is widely cited as it demonstrates that an increased intake of fruit and vegetables lowers BP. However, in the original DASH study, the increased consumption of fruit and vegetables resulted in a fall in $24 \mathrm{~h}$ ambulatory systolic/diastolic BP of 3.1/2.0 compared with $5.6 / 3 \mathrm{mmHg}$ on the DASH combination diet. The DASH combination diet provided ten portions of fruit and vegetables/d, supplying

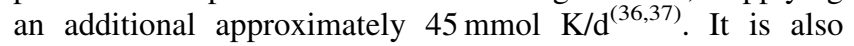
noteworthy that the DASH combination diet involved several other changes in the diet including an increased intake of wholegrain cereal, modification of fat intake, less red meat and fewer sugar-sweetened beverages. Furthermore, in the DASH studies, participants had all food provided for them on a daily basis. Adherence to the DASH diet was accompanied by several other physiological changes notably 
a reduction in body weight, changes in blood lipids and insulin sensitivity which were not observed in the present study.

In conclusion, the present results do not provide support for dietary advice to increase $\mathrm{K}$ intake, above the levels habitually consumed in the UK, for subjects with early hypertension.

\section{Acknowledgements}

We thank Tracy Dew and Roy Sherwood (King's College Hospital, London, UK) for the CRP, intracellular adhesion molecule-1, folate and homocysteine assays, Peter Lumb (St Thomas' Hospital, London, UK) for the lipid and insulin assays, Frank Kelly (King's College London) for the vitamin $\mathrm{C}$ assays, Dr Duncan Talbot (Unilever Corporate Research, Bedford, UK) for the urinary isoprostane assays, Dr Benyu Jiang and Karen McNeil (Cardiovascular Sciences Division, King's College London) for the vascular function measurements, Liz Tydeman and Robbie Gray (Nutritional Sciences King's College London) for technical help and the carotenoid and vitamin E assays, and Jo Nicholson for pilot work. T. A. B. S. was responsible for study design, data analysis and is guarantor. S. E. B. was responsible for day-to-day running of study and participated in data analysis. U. Z. M. assisted with day-to-day running of study and participated in laboratory and data analysis. P. J. C. was involved in the study design, supervised vascular measurements and participated in data analysis. All the authors contributed to writing the paper and approved the final draft. Financial support was received from the Food Standards Agency (UK) and the Department of Health via the National Institute for Health Research comprehensive Biomedical Research Centre award to Guy's \& St Thomas' NHS Foundation Trust in partnership with King's College London. The funders played no part in the study design, the collection or analysis of data, the writing of the report or the decision to submit for publication. All the authors are independent of the funders. The authors (S. E. B., U. Z. M., P. J. C. and T. A. B. S.) report no financial or personal conflicts of interest. Financial support was received from the Food Standards Agency (UK) and the Department of Health via the National Institute for Health Research comprehensive Biomedical Research Centre award to Guy's \& St Thomas' NHS Foundation Trust in partnership with King's College London. This clinical trial was registered with ISRCTN50011192.

\section{References}

1. Collins R, Peto R, MacMahon S, et al. (1990) Blood pressure, stroke, and coronary heart disease. Part 2, short-term reductions in blood pressure: overview of randomised drug trials in their epidemiological context. Lancet 335, 827-838.

2. Lewington S, Clarke R, Qizilbash N, et al. (2002) Age-specific relevance of usual blood pressure to vascular mortality: a meta-analysis of individual data for one million adults in 61 prospective studies. Lancet 360, 1903-1913.

3. Law MR, Frost CD \& Wald NJ (1991) By how much does dietary salt reduction lower blood pressure? III - analysis of data from trials of salt reduction. BMJ 302, 819-824.

4. Elliott P, Stamler J, Nichols R, et al. (1996) Intersalt revisited: further analyses of 24 hour sodium excretion and blood pressure within and across populations. Intersalt Cooperative Research Group. BMJ 312, 1249-1253.
5. He FJ, Nowson CA \& MacGregor GA (2006) Fruit and vegetable consumption and stroke: meta-analysis of cohort studies. Lancet 367, 320-326.

6. $\mathrm{Hu}$ FB \& Willett WC (2002) Optimal diets for prevention of coronary heart disease. JAMA 288, 2569-2578.

7. Bjelakovic G, Nikolova D, Gluud LL, et al. (2007) Mortality in randomized trials of antioxidant supplements for primary and secondary prevention: systematic review and meta-analysis. JAMA 297, 842-857.

8. Lin J, Rexrode KM, Hu F, et al. (2007) Dietary intakes of flavonols and flavones and coronary heart disease in US women. Am J Epidemiol 165, 1305-1313.

9. Mink PJ, Scrafford CG, Barraj LM, et al. (2007) Flavonoid intake and cardiovascular disease mortality: a prospective study in postmenopausal women. Am J Clin Nutr 85, 895-909.

10. Whelton PK, He J, Cutler JA, et al. (1997) Effects of oral potassium on blood pressure. Meta-analysis of randomized controlled clinical trials. JAMA 277, 1624-1632.

11. He FJ, Markandu ND, Coltart R, et al. (2005) Effect of shortterm supplementation of potassium chloride and potassium citrate on blood pressure in hypertensives. Hypertension $\mathbf{4 5}$, 571-574.

12. Braschi A \& Naismith DJ (2008) The effect of a dietary supplement of potassium chloride or potassium citrate on blood pressure in predominantly normotensive volunteers. $\mathrm{Br} \mathrm{J}$ Nutr 99, 1284-1292.

13. Appel LJ, Champagne CM, Harsha DW, et al. (2003) Effects of comprehensive lifestyle modification on blood pressure control: main results of the PREMIER clinical trial. JAMA 289, 2083-2093.

14. Nelson M, Erens B, Bales B, et al. (2007) Low Income Diet and Nutrition Survey. Food Consumption and Nutrient Intake, vol. 2, Norwich: The Stationery Office.

15. Hoare J, Henderson LBCJ, Prentice A, et al. (2004) The National Diet and Nutritional Survey: adults aged 19-64 years. Summary Report, vol. 5, London: TSO.

16. John JH, Ziebland S, Yudkin P, et al. (2002) Effects of fruit and vegetable consumption on plasma antioxidant concentrations and blood pressure: a randomised controlled trial. Lancet 359, 1969-1974.

17. Williams B, Poulter NR, Brown MJ, et al. (2004) British Hypertension Society guidelines for hypertension management 2004 (BHS-IV): summary. BMJ 328, 634-640.

18. Eastwood P (2009) Health Survey for England Trend Tables. London: The NHS Information Centre for Health and Social Care.

19. Gregory J, Foster K, Tyler H, et al. (1990) The Dietary and Nutritional Survey of British Adults.. London: HMSO.

20. Nichols JL, Berry SE, Mulla U, et al. (2005) Urinary potassium excretion and plasma ascorbic acid concentration as biomarkers of increased intake of fruit and vegetable intake. Proceedings of the Nutrition Society 64, 54A.

21. O'Brien E, Beevers G \& Lip GY (2001) ABC of hypertension. Blood pressure measurement. Part III - automated sphygmomanometry: ambulatory blood pressure measurement. BMJ 322, 1110-1114.

22. Corretti MC, Anderson TJ, Benjamin EJ, et al. (2002) Guidelines for the ultrasound assessment of endothelial-dependent flow-mediated vasodilation of the brachial artery: a report of the International Brachial Artery Reactivity Task Force. $J$ Am Coll Cardiol 39, 257-265.

23. Berry SE, Miller GJ \& Sanders TA (2007) The solid fat content of stearic acid-rich fats determines their postprandial effects. Am J Clin Nutr 85, 1486-1494.

24. Jauniaux E, Cindrova-Davies T, Johns J, et al. (2004) Distribution and transfer pathways of antioxidant molecules inside the first trimester human sestational sac. J Clin Endocrinol Metab 89, 1452-1458. 
25. Thurnham DI, Smith E \& Flora PS (1988) Concurrent liquidchromatographic assay of retinol, alpha-tocopherol, beta-carotene, alpha-carotene, lycopene, and beta-cryptoxanthin in plasma, with tocopherol acetate as internal standard. Clin Chem 34, 377-381.

26. Hall WL, Sanders KA, Sanders TA, et al. (2008) A high-fat meal enriched with eicosapentaenoic acid reduces postprandial arterial stiffness measured by digital volume pulse analysis in healthy men. J Nutr 138, 287-291.

27. Pufulete M, Al-Ghnaniem R, Leather AJ, et al. (2003) Folate status, genomic DNA hypomethylation, and risk of colorectal adenoma and cancer: a case control study. Gastroenterology 124, 1240-1248.

28. Theobald HE, Goodall AH, Sattar N, et al. (2007) Low-dose docosahexaenoic acid lowers diastolic blood pressure in middle-aged men and women. $J$ Nutr 137, 973-978

29. International Diabetes Federation (2008) The IDF consensus worldwide definition of the metabolic syndrome. http://www. idf.org/webdata/docs/MetS_def_update2006.pdf

30. Griendling KK \& FitzGerald GA (2003) Oxidative stress and cardiovascular injury. Part I: basic mechanisms and in vivo monitoring of ROS. Circulation 108, 1912-1916.

31. He FJ, Marciniak M, Carney C, et al. (2010) Effects of potassium chloride and potassium bicarbonate on endothelial function, cardiovascular risk factors, and bone turnover in mild hypertensives. Hypertension 55, 681-688.
32. McCall DO, McGartland CP, McKinley MC, et al. (2009) Dietary intake of fruits and vegetables improves microvascular function in hypertensive subjects in a dose-dependent manner. Circulation 119, 2153-2160.

33. Dickinson HO, Nicolson DJ, Campbell F, et al. (2006) Potassium supplementation for the management of primary hypertension in adults. The Cochrane Database of Systematic Reviews 2006, issue 3 CD004641.

34. Sacks FM, Svetkey LP, Vollmer WM, et al. (2001) Effects on blood pressure of reduced dietary sodium and the Dietary Approaches to Stop Hypertension (DASH) diet. DASHSodium Collaborative Research Group. $N$ Engl $J$ Med 344, 3-10.

35. He FJ, Marciniak M, Visagie E, et al. (2009) Effect of modest salt reduction on blood pressure, urinary albumin, and pulse wave velocity in white, black, and Asian mild hypertensives. Hypertension 54, 482-488.

36. Appel LJ, Moore TJ, Obarzanek E, et al. (1997) A clinical trial of the effects of dietary patterns on blood pressure. DASH Collaborative Research Group. $N$ Engl J Med 336, 1117-1124.

37. Conlin PR, Chow D, Miller ER, et al. (2000) The effect of dietary patterns on blood pressure control in hypertensive patients: results from the Dietary Approaches to Stop Hypertension (DASH) trial. Am J Hypertens 13, 949-955. 